\title{
Influence of type and concentration of flavinogenic factors on production of riboflavin by Eremothecium ashbyii NRRL 1363
}

\author{
A.E. Kalingan, Chung-Min Liao * \\ Department of Bioenvironmental Systems Engineering, National Taiwan University, Taipei 10617, Taiwan, ROC \\ Received 7 February 2001; received in revised form 26 August 2001; accepted 15 October 2001
}

\begin{abstract}
A study was conducted to determine the effect of various low cost organic wastes as flavinogenic factors and the various concentrations at which they induced flavinogenecity resulting in higher yields of riboflavin. A high-yielding riboflavin strain; Eremothecium ashbyii NRRL 1363 was chosen to determine the flavinogenicity. Carbon source at $50 \mathrm{~g}^{-1}$ (dextrose equivalents) of molasses and nitrogen source at $50 \mathrm{~g} \mathrm{l}^{-1}$ (weight/volume) of peanut seed cake were found to be optimal levels to yield higher riboflavin. Among the organic wastes, (beef extract, hog casings, blood meal, fish meal) hog casings in association with fish meal supported the highest yield of riboflavin. Among the different recovery processes studied, a vacuum drying process was the most efficient allowing maximum yield, followed by drying at $90{ }^{\circ} \mathrm{C}$ and freeze-drying. It is apparent from this study that inexpensive or waste organic materials could induce $E$. ashbyii to synthesize and secrete riboflavin at higher levels in the medium and this could be purified using a vacuum drying process. This bioconversion process allows us to recycle the biomaterials and produce a value-added product of economic importance. (c) 2002 Elsevier Science Ltd. All rights reserved.
\end{abstract}

Keywords: Flavinogenicity; Organic wastes; Riboflavin; Eremothecium ashbyii

\section{Introduction}

Development of biotechnological processes for the commercial production of riboflavin has been on investigation for several years. Riboflavin is a vitamin widely distributed in plants and animals. It is produced by chemical and biochemical methods (Goodwin, 1959; Hickey, 1954). Many fungi and bacteria synthesize riboflavin Ashbya gossypii (BASF, Ludwigshafen, Germany) and Candida flaveri (Archer Daniels Midland, IL, USA) are currently used for large-scale production of riboflavin (Stahman et al., 2000). Two qualities of riboflavin are produced; one with at least $96 \%$ chemical purity destined for the animal feed (Feed Grade) market and a second one with at least $98 \%$ chemical purity meant for food and medical grade. Reports indicate that the world demand for riboflavin may be 2500 tons per year, of which $60 \%$ is used as feed, $25 \%$ as medical formulations and $15 \%$ for foodstuffs enrichment. The estimated annual production by the market leaders Hoffman-La Roche (Switzerland), BASF (Germany)

\footnotetext{
${ }^{*}$ Corresponding author. Tel.: +886-2-2363-4512; fax: +886-2-23626433.

E-mail address: cmliao@ccms.ntu.edu.tw (C.-M. Liao).
}

and Archer Daniels Midland (USA) is more than 3000 tons per year (van Loon et al., 1999).

The major portion of riboflavin is used in pharmaceutical formulations; some amount in milk-substituted drinks, bread, flour, cereals, animal feed and some in aquaculture. For medical formulations, riboflavin is synthesized chemically, whereas feed concentrates for poultry and livestock are synthesized biochemically by fermentation processes using A. gossypii or Eremothecium ashbyii (Kalingan and Krishnan, 1996a,b). Fermented concentrates can also be upgraded from feed to pharmaceutical standards by repeated down stream processing and purification in accordance with FDA guidelines (FDA, 2000), which authorizes the production of riboflavin biosynthetically using $E$. ashbyii.

Since our own investigations yielded higher riboflavin from $E$. ashbyii when compared to A. gossypii (Kalingan and Krishnan, 1997a,b) we intended using E. ashbyii for this biosynthetic process and we aimed to reduce the raw material and operation cost, by selecting inexpensive carbon and nitrogen sources and optimizing the fermentation process.

Reports indicated that mutated constructs (recombinant strains) of $A$. gossypii yielded higher amount of riboflavin $\left(10-15 \mathrm{~g}^{-1}\right)$ than E. ashbyii. However, the 
possibilities of degeneration or back mutation in these strains cannot be ruled out. Perhaps similar constructs in $E$. ashbyii could also result in higher yields than the wild type.

Neither nuclear fusion nor meiosis has been observed in E. ashbyii (Batra, 1973). Hence, the probability of culture degeneration is much less and this unique character allows $E$. ashbyii to remain stable for longer period, which is interesting to investigate from a commercial point of view. Roche (1998) has proposed to replace its chemical production in 2001 by a biotechnological process with Bacillus subtilis in Germany and will save half the cost in comparison to the chemical process.

In this paper, the effect of carbon and nitrogen concentrations, including flavinogenic stimulators were investigated in order to formulate an inexpensive industrial medium, which can be commercialized. Molasses (which is rich in sugars) and peanut seed cake (which is rich in nitrogen 6.3\%) (Daphne, 1992; Kalingan and Krishnan, 1996, 1997a,b, 1998; Susan and Seymour, 1991), were abundantly available at little cost and so the same were used as carbon and nitrogen sources, respectively.

\section{Methods}

\subsection{Microorganism}

E. ashbyii (NRRL 1363) was maintained on slopes of potato dextrose agar with a composition $\left(\mathrm{g} \mathrm{l}^{-1}\right)$ of potato 250:dextrose 20:agar 25. The $\mathrm{pH}$ was adjusted to 6.5 before autoclaving at $121{ }^{\circ} \mathrm{C}$ at $103 \mathrm{kPa}$ for $15 \mathrm{~min}$. The cultures were stored at $4{ }^{\circ} \mathrm{C}$ after 5-6 days of incubation at $30^{\circ} \mathrm{C}$. Fresh slant cultures were used at 2 months interval.

\subsection{Composition of production medium}

We modified the medium of Mitsuda and Nakajima (1975) as riboflavin production medium consisting of (RP medium composition $\left(\mathrm{g}^{-1}\right)$ molasses (dextrose equivalents) 50:de-oiled peanut seedcake $50 ; \mathrm{KH}_{2} \mathrm{PO}_{4} 2 ; \mathrm{MgSO}_{4}$ $0.1 ; \mathrm{NaCl} 1 ; 80$ tween $1.8 \mathrm{ml} ; \mathrm{pH} 6.5$ ). Molasses and peanut seed cake were used instead of dextrose and peptone as carbon and nitrogen sources. Molasses (dextrose equivalents) $50 \mathrm{~g}^{-1}$ and peanut seed cake (de-oiled) $50 \mathrm{~g}^{-1}$ (weight/volume) were chosen as carbon and nitrogen sources along with other buffering salts and were autoclaved together. Peanut seed cake was crushed dried and sieved to a mesh size of $+60-40$ and then added to the medium. The $\mathrm{pH}$ was adjusted to 6.5 before autoclaving.

\subsection{Culture conditions}

In shake-flask (orbital) experiments, fungal cultures were grown at $30{ }^{\circ} \mathrm{C}$ in $500 \mathrm{ml}$ amber colored Erlen- meyer flasks containing $100 \mathrm{ml}$ production medium and seeded by an inoculum of 5\% (volume/volume) of $48 \mathrm{~h}$ grown mycelium. The flasks were shaken at $200 \mathrm{rpm}$ initially and after optimization, they were shaken at 160 rpm on an orbital shaker for 7 days. Duplicates were used for all batches of experiments and the results expressed here are averages of values obtained in each batch. Differences between duplicates had an error of $3.5 \%$.

\subsection{Stimulants used}

As a substitute for various amino acids and vitamins, organic wastes were selected as they contain large amount of numerous vitamins, amino acids and fatty acids, which could induce flavinogenecity. These wastes were chosen for this investigation to derive some benefit from the low cost amino acids and fatty acids. Fish meal used was on a "as is basis". Hog casings (small intestine used to make sausages) were finely chopped before using. Fresh beef scraps were collected from abattoir house waste and macerated overnight using $0.1 \%$ caustic potash, and then homogenized using a high-speed blender, with steaming hot water. Care was taken to maintain the extract in a semi-solid state by adding as little water as possible. Blood from freshly slaughtered swine was collected and used without any additive.

\subsection{Analytical procedure}

During fermentation cycles, samples were withdrawn aseptically, centrifuged, and the supernatant was diluted sufficiently using $0.02 \mathrm{~N}$ glacial acetic acid, and riboflavin was measured at $444 \mathrm{nM}$ in a spectrophotometer (Hitachi U 2000) (FDA, 2000). A medium containing a large amount of amino acids interfered drastically in measuring the absorbance and to eliminate such artifacts higher dilutions were used. The rate of product formation is the amount of product formed per hour. To determine the biomass production, the broth of each flask was filtered every day using Whatman No. 1 filter paper, dried in desiccators and weighed until constant weight was obtained. Specific growth rate was calculated in the region of exponential growth (Monod Kinetic model).

\section{Results and discussion}

In the first set of experiments, a large number of sources were screened for their suitability to promote growth and flavinogenesis (data not shown) among them some organic wastes as flavinogenic factors are discussed here.

The complex organic waste provides the culture medium with better growth potentiality due to its superior buffering capacity and a wider range of nutrients. After 
maximum growth of the mycelium has occurred, the initiation of sporulation of the fungus is preceded by the depletion of the sugar. Addition of sugar prior to full utilization of the same can postpone sporulation of the fungus. Batra (1973) has discussed extensively the details of fungal metabolism.

\subsection{Effect of molasses as carbon source}

To test molasses as a sole carbon source, it (instead of dextrose) was added to the RP medium at various concentrations $\left(30,40,50\right.$, and $\left.60 \mathrm{~g}^{-1}\right)$ in terms of dextrose equivalents. The initial level of $30 \mathrm{~g} \mathrm{l}^{-1}$ was selected based on the initial dextrose level used in synthetic medium. The usage of molasses as sole carbon source influenced the maximum biomass formation $\left(14.16 \mathrm{~g}^{-1}\right)$ at $50 \mathrm{~g} \mathrm{l}^{-1}$ concentration and at the same concentration the maximum riboflavin formation $\left(2.85 \mathrm{~g} \mathrm{l}^{-1}\right)$ was also observed. Further increase inhibited growth of the mycelium as well as product formation. Molasses appears to be a good carbon source for riboflavin production with an only drawback of a delayed lag phase (Kalingan and Krishnan, 1996, 1997a,b; Kalingan, 1998). An adapted inoculum preparation in molasses medium would facilitate in overcoming this problem. Miner (1940) fermented molasses media using Clostridium amylosaccharobutylpropylicum (anaerobic) and obtained a low yield of riboflavin in the dried residue. Since this process was patented, the exact concentration of molasses used is not known but the yield obtained is $60 \mathrm{mg} \mathrm{g}^{-1}$ of dried residue. Since molasses contains a complex of organic and inorganic nutrients including vitamins and amino acids, it has promoted the production of riboflavin and increased the yield.

\subsection{Effect of peanut seed cake as nitrogen source}

Comparing the effect of various concentrations of peanut seed cake $\left(30,40,50\right.$, and $\left.60 \mathrm{~g} \mathrm{l}^{-1}\right)$ (weight/volume) on biomass production and riboflavin production, $50 \mathrm{~g} \mathrm{l}^{-1}$ (weight/volume) of peanut seed cake (as nitrogen source) and $50 \mathrm{~g}^{-1}$ (dextrose equivalent) of molasses (as carbon source), gave the maximal biomass production and riboflavin production. Further increase in the concentration of peanut seed cake drastically decreased biomass production but riboflavin production level was slightly low. Hence peanut seed cake at $50 \mathrm{~g}^{-1}$ was considered the optimum nitrogen source, with $50 \mathrm{~g} \mathrm{l}^{-1}$ of molasses as carbon source. The maximal biomass and riboflavin yield obtained were 13.70 and $2.45 \mathrm{~g} \mathrm{l}^{-1}$, respectively. Beesch and Fraser (1953) obtained $1.5 \mathrm{~g} \mathrm{l}^{-1}$ of riboflavin using sugar and peanut flour (not de-oiled) as carbon and nitrogen source, respectively, at $\mathrm{pH}$ 6.7. Since it is a patent further details are not known.

\subsection{Effect of fish meal}

The product formation rate increased gradually and reached a peak value of $0.0185 \mathrm{~g} \mathrm{l}^{-1} \mathrm{~h}^{-1}$ at a concentration of $20 \mathrm{~g} \mathrm{l}^{-1}$. When compared to the effects of various other concentrations $\left(10,20,30 \mathrm{~g}^{-1}\right)$ of fish meal. Among all the amino acids, glutamic acid is found to be at the highest proportion (Longman and De Bussy, 1975). Although glutamic acid is one of the two most important precursor compounds from which the backbones of the various amino acids are formed through amino transferase, substantial increase in rate of product formation was not observed. The increase due to the effect of fish meal was also not more than $5 \%$ when compared to the control indicating that other cofactors in addition to glutamic acid were necessary to induce flavinogenicity. Further increase of the stimulant was found to inhibit the riboflavin synthesis. Fish meal contains approximately $65 \%$ protein and $10 \%$ moisture $20-25 \%$ ash. Hickey (1954) used fish meal at $3 \%$ as stimulant along with corn oil, peanut oil and cream to increase riboflavin yield. Using E. ashbyii, he employed glucose which is an expensive carbon source unviable for industrial production and economic feasibility.

\subsection{Effect of hog casings}

The rate of product formation was $0.0193 \mathrm{~g} \mathrm{l}^{-1} \mathrm{~h}^{-1}$ (highest) at $5 \mathrm{~g}^{-1}$. Hog casings contain fatty acids which are primarily made up of stearic acids (14.6\%) and linoleic acid $(9.3 \%)$. Both the saturated and unsaturated fatty acids serve as a major reserve source of energy along with other lipids. Functionally, they transport fat-soluble vitamins $\mathrm{A}, \mathrm{D}, \mathrm{E}$ and $\mathrm{K}$ from the site of synthesis to the site of activity, promoting critical and vital functions of metabolic processes involving flavinogenesis. Particularly vitamin A promotes protein and RNA synthesis, which indirectly governs flavinogenesis and there by resulting in higher riboflavin yield. A further increase in stimulant concentration inhibited the rate of product formation indicating two possible inferences; either those cells require a nutrient that is insufficient in supply or that the cytotoxic metabolic products are building up in those cells or more probably in the culture medium which blocks riboflavin synthesis through feed back inhibition.

\subsection{Effect of beef extract}

The rate of product formation increases with stimulant concentration until $25 \mathrm{~g} \mathrm{l}^{-1}$. Beef extract is rich in fatty acids and proteinaceous materials, which has drastically and proportionately promoted flavinogenesis. No compound in the stimulant seems to have inhibited the process due to the accumulation of any toxic substances. Further increase of the stimulant was 
not possible because the broth became highly viscous. Besides, more than $50 \%$ of the nitrogen source, stimulants are not added. The highest rate of riboflavin obtained was $0.0203 \mathrm{~g}^{-1} \mathrm{~h}^{-1}$ at $25 \mathrm{~g} \mathrm{l}^{-1}$.

\subsection{Effect of blood meal}

The highest rate of product $\left(0.0131 \mathrm{~g} \mathrm{l}^{-1} \mathrm{~h}^{-1}\right)$ formation was observed at $120 \mathrm{ml}^{-1}$ that was approximately $40 \%$ higher than the control values. On comparison with the effect of fish meal, the induction of flavinogenicity is 10 times higher referring to the availability of those vital elements in the blood meal incorporated substrate which were not available in fish meal incorporated substrate. Glutamic acid is found to be the highest followed by Leucine (11.02\%), Valine (6.99\%) and Lysine (6.53\%) (Lehninger et al., 1993).

One possible mechanism that can be proposed is ammonia that is enzymatically combined with glutamine catalyzed by glutamine synthetase passes through the cell membrane and serves as a port for the entry of fixed nitrogen into the cellular system. Glutamine facilitates ammonia incorporation into biomolecules at faster rate thus enabling the fungus to assimilate the nutrients and enhance secretion levels. Glutamate is transported from cytosol to the mitochondria where it undergoes oxidative deamination catalyzed by L-glutamate dehydrogenase.

The second hypothesis is glutamine contributes to the synthesis of a variety of purines pyrimidines and hexoseamines. Glutamine amide-nitrogen directly forms the nitrogen at position 3 and 9 of the purine ring that forms the central part of the riboflavin molecule, which in turn promotes the rate of riboflavin formation. No inhibitory effect was observed in the concentrations we investigated.

\subsection{Cumulative effect of the stimulants}

Among the organic wastes, considered here as stimulants, different combinations of the same (at their respective peak concentrations) with molasses $\left(50 \mathrm{~g}^{-1}\right)$ as carbon source and peanut seed cake $\left(50 \mathrm{~g}^{-1}\right)$ as nitrogen source were investigated. The various combinations with their respective concentrations used are given as follows (Fig. 1):

1. blood meal $1201 \mathrm{~m}^{-3}+$ fish meal $20 \mathrm{~g} \mathrm{l}^{-1}$;

2. blood meal $1201 \mathrm{~m}^{-3}+$ hog casings $5 \mathrm{~g}^{-1}$;

3. blood meal $120 \mathrm{1} \mathrm{m}^{-3}+$ beef extract $25 \mathrm{~g} \mathrm{l}^{-1}$;

4. fish meal $20 \mathrm{~g} \mathrm{l}^{-1}+$ hog casings $5 \mathrm{~g}^{-1}$;

5. fish meal $20 \mathrm{~g}^{-1}+$ beef extract $25 \mathrm{~g}^{-1}$;

6. hog casings $5 \mathrm{~g} \mathrm{l}^{-1}+$ beef extract $25 \mathrm{~g}^{-1}$;

7. blood meal $1201 \mathrm{~m}^{-3}+$ beef extract $25 \mathrm{~g}^{-1}+\mathrm{hog}$ casings $5 \mathrm{~g} \mathrm{l}^{-1}+$ fish meal $2 \mathrm{~g} \mathrm{l}^{-1}$.

Blood meal in association with fish meal inhibited flavinogenesis. Among all the amino acids present in fish meal, glutamic acid is the highest $(12.79 \%)$; similarly in

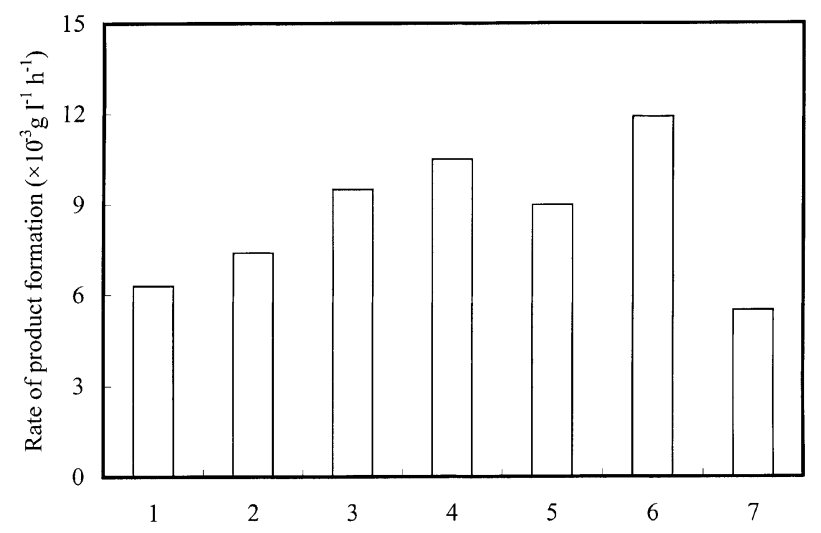

Fig. 1. Cumulative effects of stimulants. Numbers indicate the contents of the amber colored Erlenmeyer flask, which are as follows: (1) blood meal $120 \mathrm{l} \mathrm{m}^{-3}+$ fish meal $20 \mathrm{~g} \mathrm{l}^{-1}$, (2) blood meal $1201 \mathrm{~m}^{-3}+$ hog casings $5 \mathrm{~g} \mathrm{l}^{-1}$, (3) blood meal $120 \mathrm{l} \mathrm{m}^{-3}+$ beef extracts $25 \mathrm{~g} \mathrm{l}^{-1}$, (4) fish meal $20 \mathrm{~g} \mathrm{l}^{-1}+$ hog casings $5 \mathrm{~g} \mathrm{l}^{-1}$, (5) fish meal $20 \mathrm{~g}^{-1}+$ beef extract $25 \mathrm{~g} \mathrm{l}^{-1}$, (6) hog casings $5 \mathrm{~g}^{-1}+$ beef extract $25 \mathrm{~g}^{-1}$, and (7) blood meal $120 \mathrm{l} \mathrm{m}^{-3}+$ beef extract $25 \mathrm{~g} \mathrm{l}^{-1}+$ hog casings $5 \mathrm{~g} \mathrm{l}^{-1}+$ fish meal $2 \mathrm{~g} \mathrm{l}^{-1}$.

blood meal (plasma) glutamic acid is found to be the highest. In both the stimulants, glutamic acids was present in such high proportions that it might have feedback inhibited riboflavin synthesis. Overall performance of blood meal in association with the rest of all stimulants was low.

Fish meal in association with hog casings yielded the second maximum from which it can be inferred that the unsaturated fatty acids like linolenic acid $(9,12,15$-octadecatrienoic) present in fish meal were flavinogenic stimulators.

With hog casings in association with beef extract the stimulation reached a peak and it supported the maximum yield $\left(3.580 \mathrm{~g}^{-1}\right)$. It can be concluded that the presence of saturated fatty acids like palmitic (hexadecanoic) and stearic (octadecanoic) acids, present in hog casings are strong flavinogenic stimulators. Hog casing + beef extract stimulated the highest and supported the maximum rate of product formation.

Recent reports in comparison with the final yields of riboflavin indicate low cost flavinogenic material inducing flavinogenicity at higher rates than the expensive inducers. This could be due to rich organic material readily available to the fungus for assimilation of amino acids and secretion of the metabolite.

Since all the crude stimulants were not of pure grade, statistical significance could not be attributed, owing to interfering artifacts inhibiting or promoting the growth of the mycelium or riboflavin production or both of them (Venugopal and Chandra, 2000). This also prevented us from selecting a single flavinogenic factor among the crude organic matters whose contribution can be adjudged and concluded. Assuming the same had been adjudged and performed, the ultimate purpose of reducing the cost would have been defeated. 
Table 1

Comparison of recovery processes of riboflavin

\begin{tabular}{|c|c|c|c|c|}
\hline Flasks & Process $^{\mathrm{a}}$ & Volume taken (ml) & Time taken $(\mathrm{h})$ & $\%$ of Riboflavin recovery ${ }^{b}$ \\
\hline A & Drying at $37^{\circ} \mathrm{C}$ & 25 & 72 & $40-56$ \\
\hline B & Drying at $90^{\circ} \mathrm{C}$ & 25 & 72 & $85-91$ \\
\hline $\mathrm{C}$ & Freeze drying & 25 & 6 & 89 \\
\hline $\mathrm{D}$ & Spray drying & 550 & 3 & 84 \\
\hline $\mathrm{E}$ & Vacuum drying & 20 & $1 \frac{1}{2}$ & 95 \\
\hline $\mathrm{F}$ & Rotavapour & 10 & $1 \frac{1}{2}$ & 62 \\
\hline
\end{tabular}

${ }^{a}$ A 7 day fermented broth was homogenized for 10-15 min and subjected to various recovery processes.

${ }^{\mathrm{b}}$ Percentage of recovery was calculated with reference to the initial riboflavin context in an equivalent volume of unprocessed broth.

\subsection{Recovery processes of riboflavin}

Fermented broth was subjected to various recovery processes. Known quantities of the broth were treated under different conditions. Though it was found possible to dry the product at $37{ }^{\circ} \mathrm{C}$, it had the inherent drawback of prolonged processing periods (about 3 days). During this period chances are ripe for the product to deteriorate owing to possible exposure to light. Drying at $37{ }^{\circ} \mathrm{C}$ yields a poor recovery due to the prolonged exposure to indirect reflected light during incubation. Drying at $90{ }^{\circ} \mathrm{C}$ yields a better recovery where provision for maximum protection from light is given.

Table 1 shows a comparative account of the various recovery processes. It indicates vacuum drying to be the best process, followed by freeze-drying and spray drying. The recovered riboflavin has a chemical purity of $96 \%$ only. Upgrading it to medical standards needs extensive down stream processing investigations.

\section{Conclusions}

The results from the present work demonstrated that the type and concentration of the riboflavin-inducing source had an important effect on production of riboflavin by E. ashbyii. The data obtained here indicated that inexpensive and abundantly available agro-industrial by-products and organic waste originating from animal and fish resources can be used as a substrate to induce flavinogenesis. Optimum values for certain fermentation conditions have been determined and comparative studies of different recovery processes have been highlighted.

Based on our data conclusively, we recommend an optimal and industrially useful fermentation medium for riboflavin production that could consist of molasses $50 \mathrm{~g}^{-1}$ (dextrose equivalent) as sole carbon source and peanut seed cake at $50 \mathrm{~g}^{-1}$ (weight/volume) as nitrogen source, with hog casings along with beef extract as flavinogenic stimulants, at the specified concentrations. This bioprocess not only allows us to reduce the production cost but also to sustain renewable resources and thereby suite economic and ecological demands. To our knowledge data presented here is the first and foremost kind of its own.

\section{References}

Batra, L.R., 1973. Nematosporaceae (hemiascomycetidae) taxonomy pathogenecity distribution and vector relations, US Department of Agriculture. Tech. Bull. 1469 8, 71-74.

Beesch, S.C., Fraser, B.W., 1953. Riboflavin by microbiological fermentation, to publicker Industries Inc. US Patent 2.647, 704.

Daphne, D., 1992. Agriculture and food supplies. In: Daphne, D. (Ed.), Encyclopedia Britannica Book of the Year. Helen Hemingway press, London, p. 86.

FDA, 2000. Fed. register. 21, CFR 184.1697 Riboflavin: 491 (revised). Goodwin, T.W., 1959. Production and biosynthesis of riboflavin. In: Hockenhull, D.J.D. (Ed.), Progress in Industrial Microbiology, vol. 1. Heywood Press, London, pp. 369-375.

Hickey, R.J., 1954. Production of riboflavin by fermentation. In: Underkofler, L.A., Hickey, R.J. (Eds.), Industrial Fermentation, vol. 2. The Chemical Publishing Co., New York, pp. 157-190.

Kalingan, A.E., 1998. The kinetics of riboflavin secretion by Eremothecium ashbyii nrrl 1363. Bioprocess Eng. 18, 445-449.

Kalingan, A.E., Krishnan, M.R.V., 1996. Fungal fermentation of agro industrial waste to produce riboflavin. J. Indian Inst. Chem. Eng. 38 (2), 43-47.

Kalingan, A.E., Krishnan, M.R.V., 1997a. Application for agroindustrial by products for riboflavin production by Eremothecium ashbyii nrrl 1363. Appl. Microbiol. Biotechnol. 47, 226-230.

Kalingan, A.E., Krishnan, M.R.V., 1997b. Agro industrial by-products as flavinogenic stimulators for riboflavin production. Bioprocess Eng. 17, 87-91.

Kirk, Othmer, 1996a. Vitamins. In: Kirk, Othmer (Eds.), Encyclopedia of Chemical Technology, vol. 25. Wiley Interscience, New York, pp. $132-152$.

Kirk, Othmer, 1996b. Pet and livestock. In: Encyclopedia of Chemical Technology, vol. 18. Wiley Interscience, New York, pp. 341344.

Lehninger, A.L., Nelson, D.L., Cox, M.M., 1993. Amino acid production and production of urea. In: Lehninger, A.L., Nelson, D.L., Cox, M.M. (Eds.), Principles of Biochemistry. Worth Publishers, New York, pp. 515-516.

Longman, De Bussy, 1975. Meat fish and similar products. In: Longman, De Busssy (Eds.), Materials and Technology, vol. 8. Orient Longman, London, pp. 256-257.

Miner, C.S., 1940. Recovery of vitamin B components from fermentation residues. US Patent Appl. 2.202, 161.

Mitsuda, A.H., Nakajima, K., 1975. Guanosine nucleotide precursor for flavinogenesis of Eremothecium ashbyii. J. Nutri. Sci. Vitaminol. $21,331-345$. 
Roche, 1998. Roche media release. Basel April 23, Frankfurter Allgemeine, ZtG 25.4.98.

Stahman, K.-P., Revuelta, J.L., Senlberger, H., 2000. Three biotechnical processes using Ashbya gossypii, Candida famata Bacillus subtilis compete with chemical riboflavin production. Appl. Microbiol. Biotechnol. 53, 509-516.

Susan, B., Seymour, G., 1991. Molasses world production. In: Susan, B., Seymour, G. (Eds.), Commodity Yearbook. Knight Ridder Financial Publishing Group, New York, pp. 159-160. van Loon, A., Pfister, M., Doswald, S., Kupfer, E., Ludwig, B., Schurter, W., Bretzel, W., 1999. Commercial production by recombinant Bacillus subtilus: down stream processing and comparison of the composition of riboflavin produced by fermentation or chemical synthesis. J. Ind. Microbiol. Biotechnol. 22, 19-26.

Venugopal, P., Chandra, T.S., 2000. Statistical optimization of medium components for enhanced riboflavin production by a UV-mutant of Eremothecium ashbyii. Process Biochem. 36, 3137. 